Pak. j. sci. ind. res. Ser. A: phys. sci. 201356 (1) 14-18

\title{
Density Functional Theory Studies on Electronic Properties of Thiophene S-oxides as Aromatic Dienophiles for Reactivity Prediction in Diels-Alder Reactions
}

\author{
Semire Banjo \\ Department of Pure and Applied Chemistry, Ladoke Akintola University of Technology, Ogbomoso, Nigeria
}

(received May 30, 2011; revised November 30, 2011; accepted December 27, 2011)

\begin{abstract}
The reactivity of thiophene S-oxides was discussed with special emphasis on the use of thiophene S-oxides as dienophiles in Diels-Alder type reactions. The $\omega$ values obtained for thiophene S-oxide (TO) with electron-donating group $\left(-\mathrm{CH}_{3}\right)$ increased the nucleophilicity power whereas substitution with electronwithdrawing groups (such as $-\mathrm{NO}_{2}$ and $-\mathrm{CO}_{2} \mathrm{CH}_{2} \mathrm{CH}_{3}$ ) increased the electrophilicity power, indicating an increase of reactivity towards a nucleophiles. The higher the value of $\Delta \omega$ the more favourable the D-A process, therefore apart from $(4+2)$ addition reactions of these TO as diene with the typical dienophiles like 1,2-dicyanoethene and 1,2-dicyanoethne, it could be possible for TO with strong electron withdrawing substituents to serve as dienophile, e.g. heterocycles 1e and 1f. Also, from the value of $\Delta \omega$ heterocycle $1 \mathrm{~d}$ could involve in $(4+2)$ addition reactions with heterocycles $1 \mathrm{e}$ and $1 \mathrm{f}$.
\end{abstract}

Keywords: thiophene S-oxide, reactivity, global properties, density functional theory

\section{Introduction}

Thiophene S-oxide have remained an elusive species until fairly recent times; although thiophene S, S-dioxides are well-known compounds. They are viewed as building blocks with the proviso that they could be synthesized from thiophenes directly and would prove suitable cyclic dienes for cycloaddition reactions that would lead to multi-functionalized arenas (Thiemann et al., 2009). Furthermore, thiophene S-oxides have been found to exhibit a wealth of interesting reactivity (Fujii et al., 2002; Furukawa et al., 1998; 1997; Pouzet, 1997; 1995), as good dienes in Diels-Alder type reactions and add stereoselectively to a row of dienophiles (Thiemann et al., 2003; 2000a; Ho et al., 1998), however, this depends on the substituents on the frame of the thiophene-S-oxide and also on the nature of the dienophile present in these reactions (Fujii et al., 2002).

In solution and upon exposure to light, e.g. daylight, thiophene-S-oxides enjoy a much shorter lifetime and appreciable amount of thiophenes can be isolated from the ensuing mixtures (Ohira et al., 2005). Thiophene$\mathrm{S}$-oxides have been found to be active against a number of cancer cell strains. Whether this activity is attri-

E-mail: semireban@yahoo.com butable to a slight but continued deoxygenation of the compounds is still under study (Fujii et al., 2002). The use of aromatic compounds as dienes has been widely studied in D-A reactions (Thiemann et al., 2003; 2000a; 2000b; Lautens and Fillion, 1996; Paquette et al., 1982), however, their use as dienophiles is a new and interesting branch that allows to state large and versatile synthetic sequences.

Moreover, nowadays, computational chemistry methods offer a unique ability for organic chemists to generate optimal geometry structures, the structural and electronic properties of reactants and products make decisions as to which of the chemical trans-formations will occur in reactions. From the theoretical point, the differences in the stability of heterocycles are explained in terms of aromaticity and delocalization of electron densities on $\pi$ molecular orbitals. For the stable compounds, a high $\pi$ molecular orbital delocalization established between two aromatic rings, which may not be presented in the less stable isomers. It is evident that the aromaticity correlates with the thermodynamic stability of a system, and also is relationship between hardness and stability. Bird (1997), Chamizo et al. (1993) Zhou and Navangul (1990) and Parr and Pearson (1983) had reported the principle of maximum 
hardness (absolute hardness) $\eta$. For an N-electron system with total energy $E$ and $\eta$ are defined as:

$\eta=\left(\frac{\delta^{2} \mathrm{E}}{\delta \mathrm{N}^{2}}\right)_{\mathrm{v(r)}} \approx(\mathrm{I}-\mathrm{A}) \approx\left(\mathrm{E}_{\text {LUмо }}-\mathrm{E}_{\text {номо }}\right)$

In the formula I is the vertical ionization energy and A stands for the vertical electron affinity. According to the Koopmans theorem (1934), the hardness corresponds to the gap between the HOMO and LUMO orbitals. Hence, the principle of maximum hardness confirms the results that show that stability of aromatic hydrocarbons depends on HOMO-LUMO energy gap. The larger the HOMO-LUMO energy gap, the harder is the molecule. The higher HOMO energy corresponds to the more reactive molecule in the reactions with electrophiles.

The electron affinity can also be used in combination with ionization energy to give electronic chemical potential $\mu$ defined by Parr and Pearson (1983), as the characteristic of electronegativity of molecules:

$\mu=\left(\frac{\delta \mathrm{E}}{\delta \mathrm{N}}\right)_{\mathrm{v}(\mathrm{r})} \approx-\frac{1}{2}(1-\mathrm{A}) \approx \frac{1}{2}\left(\mathrm{E}_{\text {номо }}+\mathrm{E}_{\mathrm{LUMO}}\right)$

The global electrophility index $\omega$ was introduced by Parr et al. (1999) and calculated by using the electronic chemical potential $\mu$ and chemical hardness $\eta$.

$$
\omega=\frac{\mu^{2}}{2 \eta}
$$

According to the definition, this index measures the propensity of a species to accept electrons. As Domingo et al. (2002) proposes the high nucleophility and electrophility of heterocycles corresponds to opposite extremes of the scale of global reactivity indexes. A good, more reactive, nucleophile is characterized by a lower value of $\mu, \omega$ and in opposite a good electrophile is characterized by a high value of $\mu, \omega$.

In this work, as a contribution to the understanding of the reactivity of heteroaromatic dienophiles in D-A reactions with normal electron demand, the electronic properties of some selected dienophiles and some dienes were studied from a theoretical point of view. The dienes investigated are benzo[b]thiophene S-oxide, dibenzonthiophene S-oxide, 2-methylbuta-1,3-diene, Danishefky's diene and disubstituted thiophene S-oxides with electron donating groups, while the dienophiles were 1,2dicyanoethene, 1,2-dicyanoethyne and disubtituted thiophene S-oxide with electron withdrawing groups
(1)

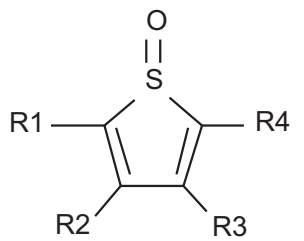

(a) $\mathrm{R} 1=\mathrm{R} 2=\mathrm{R} 3=\mathrm{R} 4=\mathrm{H}$

(b) $\mathrm{R} 1=\mathrm{R} 4=\mathrm{CH}_{3}, \mathrm{R} 2=\mathrm{R} 3=\mathrm{H}$

(c) $\mathrm{R} 1=\mathrm{R} 4=\mathrm{H}, \mathrm{R} 2=\mathrm{R} 3=\mathrm{CH}_{3}$

(d) $\mathrm{R} 1=\mathrm{R} 4=\mathrm{R} 3=\mathrm{R} 4=\mathrm{CH}_{3}$

(e) R2= R3 = H, R1 $=\mathrm{NO}_{2}, \mathrm{R} 4=\mathrm{COOCH}_{2} \mathrm{CH}_{3}$

(f) R1= R4 = H, R2 = NO $2, \mathrm{R} 3=\mathrm{COOCH}_{2} \mathrm{CH}_{3}$
(2)

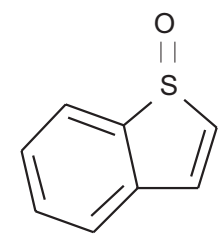

(3)

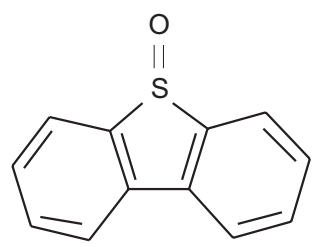

(4)

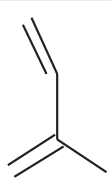

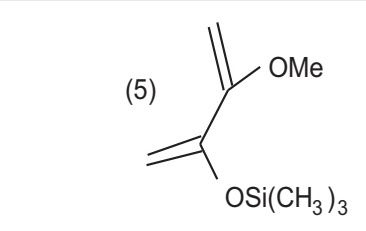

Typical dienes

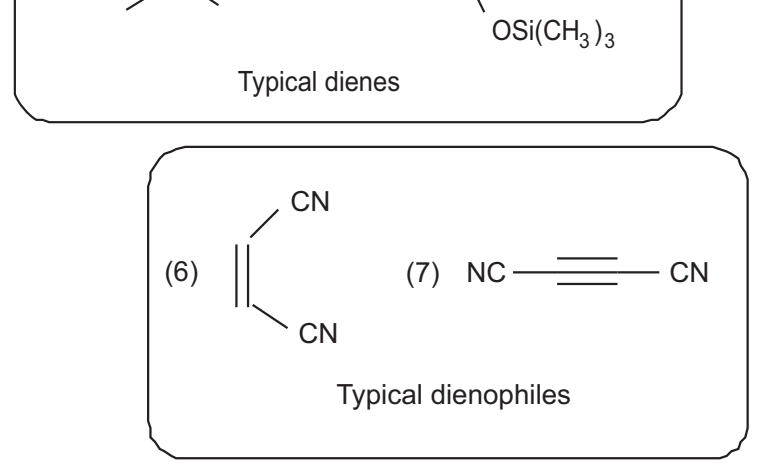

Fig. 1. The studied molecules.

(Fig. 1). In addition, the effect of dienophilic substitution on the reactivity was also examined in order to select suitably the substituents leading to the most favourable reaction conditions.

Computational details. The geometries 1-7 were fully optimized at the DFT B3LYP level of theory with a 6-31G* basis set. The basis set $6-31 \mathrm{G}^{*}$ was used for all atoms in ab initio methods, this has been used by several researchers in studying heterocycles (Armelin et al., 2009; Brasca et al., 2007; Amazonas et al., 2006; Bouzzine et al., 2005). The harmonic vibrational frequencies are positive. All calculations were performed using Spartan (2006). 
Table 1. Calculated HOMO, LUMO and global properties of studied molecules (eV)

\begin{tabular}{|c|c|c|c|c|c|c|}
\hline \multirow{2}{*}{\multicolumn{2}{|c|}{ Studied molecule }} & \multirow{3}{*}{$\begin{array}{l}\text { HOMO } \\
-6.27\end{array}$} & \multirow{3}{*}{$\begin{array}{l}\text { LUMO } \\
-1.91\end{array}$} & \multicolumn{3}{|c|}{ Global properties } \\
\hline & & & & \multirow{2}{*}{$\frac{\eta}{4.36}$} & \multirow{2}{*}{$\begin{array}{l}\mu \\
-4.09\end{array}$} & \multirow{2}{*}{$\begin{array}{l}\omega \\
1.92\end{array}$} \\
\hline 1a & Thiophene S-oxide & & & & & \\
\hline $1 b$ & 2,5-Dimethylthiophene S-oxide & -6.03 & -1.50 & 4.53 & -3.77 & 1.60 \\
\hline $1 \mathrm{c}$ & 3,4-Dimethylthiophene S-oxide & -5.99 & -1.58 & 4.41 & -3.79 & 1.63 \\
\hline $1 d$ & 2,3,4,5-Tetramethylthiophene S-oxide & -5.82 & -1.21 & 4.61 & -3.52 & 1.34 \\
\hline $1 \mathrm{e}$ & 2-Nitro-5-ethoxylcarbonylthiophene S-oxide & -7.15 & -3.75 & 3.40 & -5.45 & 4.37 \\
\hline 1f & 3-Nitro-4-ethoxylcarbonylthiophene S-oxide & -7.21 & -3.29 & 3.92 & -5.25 & 3.52 \\
\hline 2 & Benzo[b]thiophene S-oxide & -6.12 & -1.74 & 4.38 & -3.93 & 1.76 \\
\hline 3 & Dibenzothiophene S-oxide & -6.07 & -1.55 & 4.52 & -3.81 & 1.61 \\
\hline 4 & 2-Methylbuta-1,3-diene & -6.19 & -0.41 & 5.78 & -3.30 & 0.94 \\
\hline 5 & Danishefky’s diene & -5.33 & -0.17 & 5.16 & -2.75 & 0.73 \\
\hline 6 & 1,2-Dicyanoethene & -8.90 & -2.99 & 2.67 & -5.66 & 3.00 \\
\hline 7 & 1,2-Dicyanoethyne & -8.32 & -3.20 & 5.70 & -6.05 & 3.21 \\
\hline
\end{tabular}

\section{Results and Discussion}

Dienes and dienophiles classified in decreasing order of electrophilicity power $(\omega)$ are shown in Table 1 . Some global properties are also included, such as the values of chemical potential $(\mu)$ and chemical hardness $(\eta)$. It is assumed that high nucleophilicity and high electrophilicity are in opposite ends of this scale and, therefore, a molecule that shows a low electrophilicity power can be considered as a nucleophile (Parr et al., 1999). Therefore, the larger the difference between $\omega$ index of both diene and dienophile, a higher reactivity is expected. It can be appreciated that the structural and electronic characteristics induced by chemical substitution are reflected as different responses of the global electrophilicity power.

The $\omega$ values obtained for thiophene S-oxide (TO) with electron-donating group $\left(-\mathrm{CH}_{3}\right)$ increases the nucleophilicity power (i.e. decreasing in electrophilicity power) of thiophene S-oxide increases in the number of substitutions with electron-donating groups further increases the nucleophilic character of TO (i.e. 1a, 1b, $1 \mathrm{c}$ and $1 \mathrm{~d}$ in Table 2), although the position of the substitution affect reactivity of TO. For instance, substitution of $\mathrm{TO}$ at positions 2 and 5 with $-\mathrm{CH}_{3}$ increases the nucleophilicity power as compared to substitution at positions 3 and 4 ( $1 \mathrm{~b}$ and $1 \mathrm{c})$. The heterocycle 2 with fused benzene is better electrophile than 3 with two fused benzene rings.

Likewise, upon substitution of two hydrogen atoms of TO by two different electron-withdrawing groups
Table 2. Difference in electrophilicity index of dienophiles and dienes

\begin{tabular}{lllllll}
\hline \hline Cpd & $\omega$ & $\Delta \omega^{1}$ & $\Delta \omega^{2}$ & $\Delta \omega^{3}$ & $\Delta \omega^{4}$ & $\Delta \omega^{5}$ \\
\hline le & 4.37 & 3.64 & 3.43 & 3.03 & 2.77 & 2.76 \\
1f & 3.52 & 2.79 & 2.58 & 2.18 & 1.92 & 1.91 \\
7 & 3.21 & 2.48 & 2.27 & 1.87 & 1.61 & 1.60 \\
6 & 3.01 & 2.27 & 2.07 & 1.67 & 1.41 & 1.40 \\
1a & 1.92 & 1.19 & - & - & - & - \\
2 & 1.76 & 1.03 & - & - & - & - \\
1c & 1.63 & - & - & - & - & - \\
3 & 1.61 & - & - & - & - & - \\
1b & 1.60 & - & - & - & - & - \\
1d & 1.34 & - & - & - & - & - \\
4 & 0.94 & - & - & - & - & - \\
5 & 0.73 & - & - & - & - & - \\
\hline \hline
\end{tabular}

*The molecules are arranged in order of $\omega$ values calculated at B3LYP/6-31G*

$\Delta \omega=\left(\omega_{\text {Dienophile }}-\omega_{\text {Diene }}\right)$

$\Delta \omega^{1}=\left(\omega_{\text {Dienophile }}-\omega_{5}\right), \Delta \omega^{2}=\left(\omega_{\text {Dienophile }}-\omega_{4}\right)$,

$\Delta \omega^{3}=\left(\omega_{\text {Dienophile }}-\omega_{1 \mathrm{~d}}\right), \Delta \omega^{4}=\left(\omega_{\text {Dienophile }}-\omega_{1 \mathrm{~b}}\right)$,

and $\Delta \omega^{5}=\left(\omega_{\text {Dienophile }}-\omega_{3}\right)$,

(- $\mathrm{NO}_{2}$ and $-\mathrm{CO}_{2} \mathrm{CH}_{2} \mathrm{CH}_{3}$ ) the electrophilicity power further increases, thus indicating an increase of reactivity towards a nucleophile (1e and 1f). Similarly, electronwithdrawing groups at positions 2 and 5 of TO increase the electrophilic character as compared to substations 
at 3 and 4 (Tables 1 and 2). The observed behaviour in these pairs of isomers ( $1 \mathrm{~b}$ and $1 \mathrm{c}, 1 \mathrm{e}$ and $1 \mathrm{f}$ ) was supported by the values of dipole moments and stability. Isomer $1 \mathrm{~b}$ with higher nucleophilic character had lower HOMO energy, higher LUMO energy, lower dipole moment and higher stability, whereas isomer $1 \mathrm{c}$ with lower nucleophilic character had higher HOMO, lower LUMO, higher dipole moment and less stability. However, in isomers 1e and $1 \mathrm{f}$ the observed properties were in opposite in the sense that $1 \mathrm{e}$ with higher electrophilic character had the properties corresponded to that of $1 \mathrm{c}$.

The reactivity of the D-A process depends on the energy separation between frontier molecular orbitals (FMO) of reagents, HOMO of the diene, and LUMO of dienophile. A small energy difference between interacting FMO will contribute to a higher stabilization of the transition state, therefore, all factors that decrease HOMO-LUMO distance will increase reaction rate. Then, from the energy point of view, the most favourable HOMO-LUMO interaction will be that of less $\Delta \mathrm{E}$ and high value of difference in $\omega$ of dienophile and $\omega$ of diene $(\Delta \omega)$ as shown in Table 2 . The higher the value of $\Delta \omega$ the more favourable the D-A process, therefore, apart from $(4+2)$ addition reactions of these TO as diene with the typical dienophiles like 1,2-dicyanoethene and 1,2-dicyanoethyne, it could be possible for TO with strong electron withdrawing substituents to serve as dienophile e.g. heterocycles 1e and 1f. Also, from the value of $\Delta \omega$ heterocycle $1 \mathrm{~d}$ could involve in $(4+2)$ addition reactions with heterocycles $1 \mathrm{e}$ and $1 \mathrm{f}$.

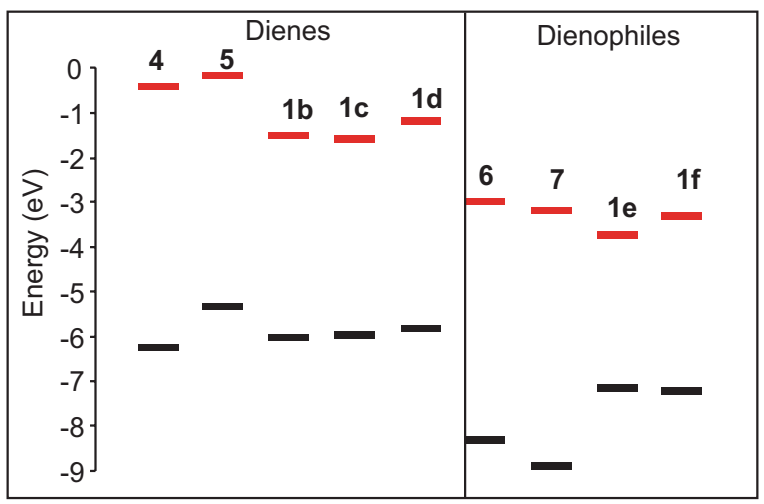

Fig. 2. The frontal molecular orbital (FMO) energies showing the effect of substitution on thiophene S-oxide (TO).
Figure 2 shows FMO energies for 2, 5-dimethylthiophene S-oxide (1b), 3,4-dimethylthiophene S-oxide (1c), 2,3,4,5tetramethylthiophene S-oxide (1d), 2-methylbuta-1,3-diene (4) and Danishefky's diene (5) as dienes and 2-nitro-5ethoxylcarbonylthiophene S-oxide (1e), 3-nitro-4ethoxylcarbonylthiophene S-oxide (1f), 1,2-dicyanoethene (6) and 1,2-dicyanoethyne (7) as dienophiles. This figure reveals the effect on substitution on the TO, it can be clearly seen that electron-withdrawing substituents decrease LUMO energy, which would result in an acceleration of the reaction rate. These results are in agreement with those obtained by analysing the global electrophilicity index (Table 1).

\section{Conclusion}

Global electrophilic index is a useful tool for explaining the effect of substituents in the diene/dienophile interacting pair. Upon substitution of TO with electronwithdrawing groups, there is an increase in $\omega$ index, thus reflecting a higher electrophilic character. On the other hand, substitution of $\mathrm{TO}$ with electron-donating groups there is a decrease in $\omega$ index, thus reflecting a higher global nucleophilic nature.

Based on such theoretical calculations the influence of the combination and positional relationship of the substituents of each dienophile can be analysed in order to develop most suitable reactions for the design of possible precursor to be integrated in synthetic sequences. It could be possible for TO with strong electron withdrawing substituents to serve as dienophile and from the value of $\Delta \omega$ heterocycle 1d could involve in $(4+2)$ addition reactions with heterocycles $1 \mathrm{e}$ and 1f.

\section{References}

Amazonas, J.G., Guimaraes, J.R., Santos Costa, S.C., Laks, B., Del Nero, J. 2006. Theoretical modeling of low band-gap organic oligomers. Journal of Molecular Structure (Theochem), 759: 87-91.

Armelin, E., Bertran, O., Estrany, F., Salvatella, R., Alemán, C. 2009. Characterization and properties of a polythiophene with a malonic acid dimethyl ester side group. European Polymer Journal, 45: 2211-2221.

Bird, C.W. 1997. Heteroaromaticity. 10. The direct calculation of resonance energies of azines and azoles from molecular dimensions. Tetrahedron, 53: 2497-2502.

Bouzzine, S.M., Bouzakraoui, S., Bouachrine, M., 
Hamidi, M. 2005. Density functional theory (B3LYP/6-31G*) study of oligothiophenes in their aromatic and polaronic states. Journal of Molecular Structure (Theochem), 726: 271-276.

Brasca, R., Kneeteman, M.N., Pedro, M.E.M. 2007. Calculation of electronic properties of aromatic dienophiles for reactivity prediction in Diels-Alder reactions. Molecular Medicinal Chemistry, 12: 54-57.

Chamizo, J.A., Morgado, J., Sosa, O. 1993. Organometallic aromaticity. Organometalliks, 12: 5005-5007.

Domingo, L.R., Aurell, M., Contreras, M., Perez, P. 2002. Quantitative characterization of the local electrophilicity of organic molecules. Understanding the regioselectivity on Diels-Alder reactions. Journal of Physical Chemistry A, 106: 6871-6876.

Fujii, H., Ohira, D., Mataka, S., Thiemann, T. 2002. Cycloaddition of thiophene $S$-oxides to allenes and to benzyne. Sixth International Electronic Conference on Synthetic Organic Chemistry (ECSOC-6). 1-30, http://www.mdpi.org/ecsoc-6.

Furukawa, N., Zhang, S.Z., Horn, E., Takahashi, S., Sato, S., Yokoyama, M., Yamaguchi, K. 1998. X-ray crystallographic analysis of 2,5-bis(diphenylmethylsilyl) thiophene monoxides and the Diels-Alder reaction of thiophene monoxide with dienophiles. Heterocycles, 47: 793-809.

Furukawa, N., Zhang, S., Sato, S., Higaki, M. 1997. Simple procedure for the synthesis of 2, 5-Bis (silylated) thiophene S-oxides with $\mathrm{m}$-chloroperbenzoic acid in the presence of $\mathrm{BF}_{3} \times \mathrm{Et}_{2} \mathrm{O}$. Heterocycles, 44: 61-66.

Ho, M.T., Treiber, A., Dansette, P. M. 1998. Oxidation of 2-(4-chlorobenzoyl)-thiophene into 1-oxide DielsAlder dimers, sesquioxide and a sulfone-water adduct.Tetrahedron Letters, 39: 5049-5052.

Koopmans, T. 1934. Ordering of wave functions and eigenvalues to the individual electrons of an atom. Physica, 1: 104-113.

Lautens, M., Fillion, E. 1996. Diastereoselective intermolecular [4+3] cycloadditions via an extended transition state, Journal of Organic Chemistry, 61: 7994-7995.

Ohira, D., Watanabe, M., Miura, A., Mataka, S., Thiemann, T., Iniesta Valcarcel, J., Walton, D.J. 2005. The photochemistry of thiophene $S$-oxides. Photochemical and Photobiological Sciences, 4: 808-816.

Parr, R.G., Szentpaly, L., Liu, S. 1999. Electrophilicity index. Journal of American Chemical Society, 121: 1922-1924.

Parr, R.G., Pearson, R.G. 1983. Absolute hardness: Companion parameters to absolute electronegativity. Journal of American Chemical Society, 105: 75127515.

Paquette, L., Wyvratt, M., Berk, H., Moerch, R. 1982. A strategy for the synthesis of monosubstituted dodecahedrane and the isolation of an isododecahedrane. Journal of American Chemical Society, 104: 4502-4503.

Pouzet, P., Erdelmeier, I., Ginderow, D., Mornon, J.-P., Dansette, P. M., Mansuy, D. 1997. Thiophene 1-oxides. V. Comparison of the crystal structures and thiophene ring aromaticity of 2,5-diphenylthiophene, its sulfoxide and sulfone. Journal of Heterocyclic Chemistry, 34: 1567-1579.

Pouzet, P., Erdelmeier, I., Ginderow, D., Mornon, J.P., Dansette, P., Mansuy, D. 1995. Thiophene S-oxide: convenient preparation, first complete structural characterization and unexpected dimerization of them, 2,5-diphenylthiophene 1-oxide. Journal of the Chemical Society, Chemical Communication, (Issue No.4), 38: 473-474.

Spartan 2006, Wavefunction Inc., Irvine, CA, 92612, USA.

Thiemann, T., Walton, D.J., Brett Ana, O., Iniesta, J.,Arken. F., Li, Y-Q. 2009. The chemistry of thiophene S-oxides and related compounds, Issue $5^{\text {th }}$, Eurasian Conference on Heterocyclic Chemistry, Archive for Organic Chemistry (ARKIVOC), ix: 96-113.

Thiemann, T., Fujii, H., Ohira, D., Arima, K., Li, Y.Q., Mataka, S. 2003. Cycloaddition of thiophene S-oxides to allenes, alkynes and to benzyne, New Journal of Chemistry, 27: 1377-1384.

Thiemann, T., Ohira, D., Li, Y. Q., Sawada, T., Mataka, S., Rauch, K., Noltemeyer, M., de Meijere, A. 2000a. [4+2] Cycloaddition of thiophene Smonoxides to activated methylenecyclopropanes, Journal of Chemical Society, Perkin Transactions, 1: 2968-2975.

Thiemann, T., Li, Y.Q., Thiemann, C., Sawada, T., Ohira, D., Tashiro, M., Mataka, S. 2000b. Oxidative cycloaddition of molecules with multiple thiophene cores. Heterocycles, 52: 1215-1230.

Zhou, Z., Navangul, H.V. 1990. Absolute hardness and aromatisity: MNDO study of benzenoid hydrocarbons. Journal of Physical and Organic Chemistry, 3: 784-788. 